\title{
A PRODUÇÃO DE CONHECIMENTOS SOBRE ATENDIMENTO EDUCACIONAL ESPECIALIZADO: UM ESTUDO COMPARADO NACIONAL
}

\author{
LA PRODUCCIÓN DE CONOCIMIENTOS SOBRE ATENDIMIENTO EDUCACIONAL \\ ESPECIALIZADO: UN ESTUDIO COMPARADO NACIONAL
}

THE PRODUCTION OF KNOWLEDGE ON SPECIALIZED EDUCATIONAL CARE: A COMPARATIVE NATIONAL STUDY

\author{
Mariangela Lima de ALMEIDA ${ }^{1}$ \\ Josiane Beltrame MILANESI ${ }^{2}$ \\ Enicéia Gonçalves MENDES ${ }^{3}$
}

RESUMO: Este artigo, com foco na perspectiva comparada dos estudos em Educação Especial, toma por base de análise duas pesquisas colaborativas que versaram sobre as políticas escolarização para os alunos Público-alvo da Educação Especial (PAEE), em dois municípios da região sudeste do Brasil: Rio Claro (SP) e Santa Maria de Jetibá (ES). Por meio do diálogo crítico com os atores de cada contexto, reflete o conhecimento sobre as políticas de atendimento educacional especializado (AEE) em ação/instituída no cenário nacional. A análise foi construída a partir de duas pesquisas independentes. Dois pontos de convergência marcam esses estudos em suas perspectivas e princípios teórico-metodológicos: a colaboração entre universidade e redes de ensino no processo de construção de conhecimentos e grupos focais como instrumentos de coleta de dados. Muitas reflexões ainda são necessárias para compreender as políticas a partir dos atores que as colocam em uso, seus discursos e as práticas institucionais que emergem do processo de implementação das políticas pelos profissionais que atuam no nível da prática. As análises mostram que no contexto dos municípios essa política sofre múltiplas traduções e interpretações em vários níveis, assumindo diferentes contornos. Em se tratando do AEE, ofertado nas SRM, as políticas voltadas para esta forma de atendimento são recentes e, por isso, há muito que se constituir para se saber de fato como ensinar nestas salas, bem como conceber um trabalho colaborativo com a sala comum.

PALAVRAS-CHAVE: Educação especial. Atendimento educacional especializado. Estudo comparado.

RESUMEN: Este artículo, con foco en la perspectiva comparada de los estudios en Educación Especial, toma por base de análisis dos investigaciones colaborativas que versaron sobre las políticas escolarización para los alumnos Público objetivo de la

1 Universidade Federal do Espírito Santo (UFES), Vitória - ES - Brasil. Docente dos Programas de PósGraduação do Mestrado em Educação Modalidade Profissional e Ensino, Ed. Básica e Formação de Professores. ORCID: <http://orcid.org/0000-0002-7092-2583>. E mail: mlalmeida.ufes@ gmail.com

${ }^{2}$ Prefeitura Municipal de Cariacica (PMC), Cariacica - ES - Brasil. Prof. ${ }^{a}$ Dr. ${ }^{a}$ de Atendimento Educacional Especializado. ORCID: <http://orcid.org/0000-0002-5486-5937>. E-mail: milanesi.josiane@ gmail.com

${ }^{3}$ Universidade Federal de São Carlos (UFSCar), São Carlos - SP - Brasil. Docente do Programa de PósGraduação em Educação Especial. ORCID: <http://orcid.org/0000-0003-3673-0681>. E-mail: egmendes@ufscar.br 
Educación Especial (PAEE), en dos municipios de la región sudeste de Brasil: Río Claro (SP) y Santa Maria de Jetibá (ES). Por medio del diálogo crítico con los actores de cada contexto, refleja el conocimiento sobre las políticas de atención educativa especializada (AEE) en acción / instituida en el escenario nacional. El análisis fue construido a partir de dos investigaciones independientes. Dos puntos de convergencia marcan estos estudios en sus perspectivas y principios teórico-metodológicos: la colaboración entre universidad y redes de enseñanza en el proceso de construcción de conocimientos y grupos focales como instrumentos de recolección de datos. Muchas reflexiones todavía son necesarias para comprender las políticas a partir de los actores que las ponen en uso, sus discursos y las prácticas institucionales que emergen del proceso de implementación de las políticas por los profesionales que actúan a nivel de la práctica. Los análisis muestran que en el contexto de los municipios esta política sufre múltiples traducciones e interpretaciones en varios niveles, asumiendo diferentes contornos. En lo que se refiere al AEE, ofrecido en las SRM, las políticas dirigidas a esta forma de atención son recientes $y$, por eso, hay mucho que constituirse para saber cómo enseñar en estas salas, así como concebir un trabajo colaborativo con la sala común.

PALABRAS-CLAVE: Educación especial. Atención educativa especializada. Estudio comparado.

ABSTRACT: This article focuses on the comparative perspective of special education studies based on two collaborative research studies that focused on the schooling policies for the Special Education Target Audience (PAEE) students in two municipalities in the southeastern region of Brazil: Rio Claro (SP) and Santa Maria de Jetibá (ES). Through the critical dialogue with the actors in each context, it reflects the knowledge about the policies of specialized educational assistance (AEE) in action / instituted in the national scenario. The analysis was based on two independent researches. Two points of convergence mark these studies in their perspectives and theoretical and methodological principles: the collaboration between university and teaching networks in the process of knowledge construction and focus groups as instruments of data collection. Many reflections are still needed to understand the policies from the actors that put them in use, their speeches and the institutional practices that emerge from the process of policy implementation by professionals who act at the practice level. The analyzes show that in the context of the municipalities this policy suffers multiple translations and interpretations in several levels, assuming different contours. When it comes to ESA, offered in the SRM, the policies focused on this form of service are recent and, therefore, there is much to be done to know in fact how to teach in these rooms, as well as conceive a collaborative work with the common room.

KEYWORDS: Special education. Specialized educational assistance. Comparative study.

\section{Introdução}

Em vários países o movimento de inclusão social e escolar das pessoas com deficiência conquistou, nas últimas décadas, sustentação ideológica, política e científica. No Brasil, a partir dos anos 1990, a legislação educacional expressa a tentativa de promover a democratização do espaço escolar. No curso das diretrizes políticas, a "Política Nacional de 
Educação Especial na Perspectiva da Educação Inclusiva" (PNEE-EI), do Ministério da Educação (MEC) (BRASIL, 2008) reforçou o atendimento no ensino comum, o que se diferenciou das políticas anteriores quando se priorizava um atendimento substitutivo ao ensino comum ${ }^{4}$.

Diante desse contexto, os estudos comparados na área de Educação Especial têm sido colocados em relevo perante sua contribuição no avanço do conhecimento sobre políticas e práticas de escolarização das pessoas com deficiência. Ao mesmo tempo, busca-se uma (re)definição teórico-metodológica dessa perspectiva investigativa, de modo a nos possibilitar “[...] o exercício crítico de problematização da própria noção de comparação para esquivar-se da inexorabilidade dos procedimentos generalistas que inviabilizam a apreensão da complexidade" (MOREIRA; REZENDE; ISOBE, 2013, p. 3) sobre o processo de inclusão escolar.

Este artigo, com foco na discussão sobre a perspectiva comparada, toma por base de análise duas pesquisas colaborativas que versaram sobre as políticas escolarização para os alunos Público-alvo da Educação Especial (PAEE) ${ }^{5}$, em dois municípios da região sudeste do Brasil: Rio Claro (SP) e Santa Maria de Jetibá (ES). Por meio do diálogo crítico com os atores de cada contexto, buscamos adensar o conhecimento sobre as políticas de atendimento educacional especializado (AEE) em ação/instituída no cenário nacional. Mainardes (2006) destaca que a política educacional possui natureza complexa e controversa, o que exige em seu processo de análise, a ênfase nos processos micropolíticos e na ação dos profissionais que lidam com as políticas no nível local.

Diferentes pesquisas em Educação Especial na perspectiva dos estudos comparados têm buscado, nos últimos anos, compreender o país a partir de si mesmo, considerando suas dimensões territoriais, configurações sociais e culturais que tomam contornos peculiares a cada região, estado ou município. Assim, este texto focaliza as configurações de comparação dos contextos locais e seus sujeitos na busca de estabelecer o diálogo com o outro - com gestores e professores das redes municipais de ensino sobre o AEE. Como aponta Cararo (2015, p. 24) “[...] a melhor comparação a ser feita é do Brasil com o próprio Brasil”.

Inicialmente retomamos as diretrizes atuais para o AEE no diálogo com autores da área de Educação Especial. Posteriormente, discute-se a perspectiva teórico-metodológica e o

\footnotetext{
${ }^{4}$ Ainda com direcionamentos mais precisos voltados ao recebimento/atendimento do PAEE em escolas comuns da rede pública de ensino o poder público não deixou de investir financeiramente no terceiro setor.

${ }^{5}$ Atualmente, no campo da educação, segundo as normas oficiais, essas pessoas são consideradas o PAEE que é oficialmente composto por pessoas com deficiência, transtornos globais do desenvolvimento e altas habilidades/superdotação.
} 
contexto de produção dos dados contextualizando as duas redes de ensino. Num terceiro tópico, refletimos as políticas de AEE instituídas por meio das narrativas dos gestores e professores.

\section{O Atendimento Educacional Especializado no contexto da política de Educação Especial}

O contexto de proposições e normatizações legais em âmbito nacional nas últimas décadas, passou a exigir dos estados e municípios a implementação de políticas públicas que assegurem a educação dos estudantes da Educação Especial no ensino comum. Estudos que analisam esse movimento em municípios brasileiros (PRIETO; PAGNEZ; GONZALEZ, 2014; CAIADO; LAPLANE, 2009; ALMEIDA; JESUS; CUEVAS, 2013) indicam a busca do órgão gestor municipal em assegurar que as reformas propostas sejam efetivadas em seus sistemas de ensino. Sem dúvidas, uma dessas reformulações diz respeito ao AEE nas escolas das redes regulares de ensino.

Ao analisar os movimentos da política de Educação Especial no Brasil ao longo do período 2001-2010, Garcia (2013) constatou que a partir de 2008 a ênfase em relação à Educação Especial recaiu na disponibilização de recursos e serviços e não mais em uma proposta pedagógica. Deste modo, o conceito de Educação Especial parece voltar-se ao AEE reduzido as Salas de Recursos Multifuncionais (SRM). A autora, destaca, ainda, que a Educação Especial já vinha desde a Resolução nº 02/2001 (BRASIL, 2001) sendo considerada como serviço, podendo substituir o ensino regular. "Agora, o programa de implementação de SRM como lócus do AEE reitera essa compreensão de educação como serviço, enquadrandose em um modelo de gestão gerencial. Registra-se, contudo, que a função substitutiva da Educação Especial foi retirada" (GARCIA, 2013, p. 107). A promulgação da Resolução no 04 em 2009, que dispõe acerca da operacionalização da PNEE-EI, contribuiu para a compreensão de como deveria acontecer o AEE.

Acerca do grupo elegível para receber o AEE, considerando as políticas públicas mais recentes, percebe-se que houve uma restrição definindo este público como sendo os alunos com deficiência, transtornos globais do desenvolvimento e altas habilidades/superdotação (BRASIL, 2009). Este fato apresenta mudanças em relação a população entendida como de domínio da Educação Especial. O público a ser atendido no AEE, ou seja, considerados alunos PAEE, tornou-se mais restritivo e associado a impedimentos na esfera orgânica. 
Essas diretrizes ganham contornos nos municípios brasileiros a partir do programa de implantação das SRM lançado em 2005 pelo MEC. Com objetivo de avaliar as contribuições dessa proposta, em 2010 iniciou-se um estudo em âmbito nacional denominado Observatório Nacional de Educação Especial: Estudo em Rede Nacional sobre as Salas de Recursos Multifuncionais das Escolas Comuns.

No que tange ao eixo temático Organização e funcionamento das SRM, os dados indicaram que, apesar do direito ao AEE estar garantido na letra da lei, de fato, a maioria desses estudantes ainda permanece exclusivamente em classes comuns. Os dados do censo escolar de 2016 indicam que apenas 41\% dos estudantes tem recebido o AEE (INEP, 2016). Os resultados indicaram ainda que no AEE há predominância no atendimento para alunos identificados como tendo deficiência intelectual (DI), que frequentam majoritariamente turmas de Ensino Fundamental. Sobre a organização e o funcionamento do AEE nas SRM constatou-se que as práticas no AEE são muito variadas e dependem da compreensão que os professores têm desse serviço, a SRM (MENDES; TANNÚS-VALADÃO, 2015).

Diante desse panorama, acreditamos que estudos que busquem aprofundar a compreensão dos modos como o AEE têm sido incorporados por gestores e professores em diferentes municípios sejam de relevância para a produção científica brasileira em Educação Especial. A interpretação e tradução das políticas dizem do modo como os atores do contexto concebem o conhecimento que ali estão. Habermas (1987, p. 24) nos diz que "[...] a racionalidade tem menos a ver com o conhecimento, ou com a aquisição de conhecimento, e mais com a forma como os sujeitos capazes de linguagem e de ação fazem uso do conhecimento". Esse pensamento propicia o diálogo com os profissionais da Educação Especial e do ensino comum, acerca de como os conhecimentos e os saberes são utilizados na materialização das políticas de inclusão escolar.

\section{O percurso metodológico e os contextos dos municípios pesquisados}

Este trabalho ancora-se na abordagem qualitativa, teórico-metodológica sustentada na relação dinâmica, contextual e temporal entre o pesquisador e o objeto de estudo. Trata-se de uma análise a partir dos estudos comparados em Educação Especial, sustentada nos postulados habermasianos que enfatizam a racionalidade comunicativa (HABERMAS, 1987).

A análise aqui produzida foi construída a partir de duas pesquisas independentes realizadas na perspectiva da pesquisa colaborativa. Embora os contextos de produção dos 
estudos tenham se dado em tempo-espaços diferentes, podemos destacar pontos de convergência em suas perspectivas e princípios teórico-metodológicos:

a) Ambos estudos se sustentam na perspectiva da colaboração entre universidade e redes de ensino no processo de construção de conhecimentos pela via da pesquisa, ensino e extensão. Desse modo, os estudos buscam avançar com o conhecimento na área de Educação Especial na perspectiva da inclusão, ao mesmo tempo que contribuem para o desenvolvimento profissional de gestores e professores, bem como para a elaboração de novas práticas e políticas educacionais.

b) Os grupos focais foram utilizados como instrumentos de coleta de dados, para se ter acesso aos acontecimentos no próprio movimento dos grupos, conhecer suas realidades e "negociar" demandas. A estratégia dos grupos focais (GATTI, 2005), propiciaram um movimento de engajamento de seus participantes, nos quais buscamos ter acesso aos acontecimentos no próprio movimento dos grupos.

Busca-se neste texto, a partir de uma análise comparada dos contextos educacionais capixaba e paulista, conhecer e compreender as experiências educacionais nos municípios foco dos estudos, no tempo e no espaço, a fim de fazer dialogar como as práticas de AEE têm sido ofertadas aos estudantes PAEE.

Iniciamos pela análise de conteúdos, conforme sugere Bardin (1994). Considerando a perspectiva teórico-metodológica do estudo, buscamos dialogar com os profissionais das redes de ensino por meio dos grupos focais. Assumimos a premissa de que:

No lugar do sujeito solitário, que se volta para objetos e que, na reflexão, se toma a si mesmo por objeto, entra não somente a ideia de um conhecimento linguisticamente mediatizado e relacionado com o agir, mas também o nexo da prática e da comunicação quotidianas, no qual estão inseridas as operações cognitivas que têm desde a origem um caráter intersubjetivo e ao mesmo tempo cooperativo. (HABERMAS, 2003, p. 25)

É imprescindível considerar que quando falamos em municípios no interior capixaba e paulista, reportamos a contextos diferenciados no que tange a dados demográficos, aspectos econômicos, e dessa forma buscamos construir categorias analíticas que permitissem estar atentas aos diferentes modos de como uma determinada prática educacional é construída e apropriada pelos sujeitos. Desse modo, assumimos como princípio que a investigação comparada exige o escrutínio dos discursos de naturalização e homogeneização das práticas educativas, bem como as estratégias de conformação da ação dos sujeitos aos determinismos sociais (RESENDE; ISOBE; MOREIRA, 2013). 


\section{As configurações do atendimento educacional especializado nos municípios de Rio Claro/SP e Santa Maria de Jetibá/ES}

Ao nos propormos realizar uma análise comparada entre dois municípios com traços tão peculiares como Santa Maria de Jetibá/ES e Rio Claro/SP, algumas indagações nos provocam: É possível observar que embora os períodos de coleta dos dados deem-se em momentos diferentes, outros fatores podem incidir no processo de implementação da política. Mais que a marca do tempo, nesse caso, poderia ser que os contextos territoriais locais no que tange aos aspectos econômicos, políticos e sociais de cada estado e município demarquem o lugar da "política proposta" e da "política em uso" (BALL; BOWE, 1992).

O município de Rio Claro, localizado no Estado de São Paulo e pertencente à Região Administrativa de Campinas, encontra-se no centro-leste do Estado, situando-se a $190 \mathrm{~km}$ da capital paulista. Sua população é estimada em 186.253 habitantes, cobrindo uma área de 499 $\mathrm{km}^{2}$ (IBGE, 2010). Composto por uma população de aproximadamente 38.850 habitantes de descendência europeia pomerana, o município de Santa Maria de Jetibá - ES tem uma área de $735.579 \mathrm{Km}^{2}$ e densidade demográfica 46,46 habitantes por $\mathrm{km}^{2}$. A economia municipal predominantemente hortifrutigranjeiros e conta com a mão de obra familiar em pequenas propriedades.

No que se refere as redes municipais de ensino, Rio Claro possuía 52 unidades, de Educação Infantil, compreendendo as Etapas I (para crianças de quatro meses a três anos) e Etapa II (quatro e cinco anos), Ensino Fundamental (do $1^{\circ}$ ao $5^{\mathrm{a}}$ ano e uma escola agrícola de $5^{\mathrm{a}}$ à $8^{\mathrm{a}}$ séries), Educação de Jovens e Adultos I (EJA) (Termo I ao IV) e EJA II (correspondente ao ensino da $5^{\mathrm{a}}$ à $8^{\mathrm{a}}$ séries). Ao todo, estavam matriculados 3.394 alunos na Educação Infantil Etapa I, 3.987 alunos na Educação Infantil Etapa II, 8.881 no Ensino Fundamental, Educação de Jovens e Adultos I, com 346 alunos, e EJA II, com 723 alunos, totalizando 17.331 alunos matriculados naquela rede municipal.

A rede municipal de ensino de Santa Maria de Jetibá contava com quatro creches, cinco Centros de Educação Infantil, duas Escolas Municipais de Educação Infantil, 31 Escolas Unidocentes e Pluridocentes e seis escolas de Ensino Fundamental completo. De um total de 3.715 estudantes, 2.241 estavam matriculados no Ensino Fundamental, 1.474 matriculados na Educação Infantil e do total de matriculados, 72 deles eram considerados alunos PAEE.

Considerando que a implementação das SRM iniciou-se no país em 2005-2007 e o processo de coleta de dados nos municípios ocorrem em períodos diferentes (Rio Claro coletados em 2011 e Santa Maria de Jetibá em 2016-2017), de que modo esse espaço-tempo 
de cinco anos poderia influenciar na "tradução" dessa política de AEE? De que modo, esses dados retratam momentos históricos em cada um dos municípios?

Em Rio Claro, em 2009 o município começou a receber apoio financeiro para a criação de SRM e, no momento do estudo, havia 18 salas para o AEE (17 do Tipo I e uma do Tipo II), tendo 18 professores, das quais 14 participaram do estudo. Dessas 18 SRM, oito funcionavam nos períodos matutino e vespertino, seis, no período matutino, e quatro, no período vespertino. Conforme informado pela coordenadora da Educação Especial de Rio Claro, no total, essas salas atendiam a 247 alunos, sendo 198 alunos cadastrados oficialmente e 49 alunos em avaliação ou considerados limítrofes, os quais não eram cadastrados oficialmente e, portanto, não recebiam financiamento para o atendimento, embora frequentasse a SRM.

Em Santa Maria de Jetibá em 2010 havia sido criado o Centro de Referência de Educação Inclusiva (CREI) como parte integrante da Secretaria Municipal de Educação (SECEDU), por meio do decreto 091/2010 com a ideia inicial de desvincular o conceito de atendimento clínico e garantir um trabalho pedagógico sistematizado para as crianças PAEE. Somente em 2014 é implementada a primeira SRM em uma escola da rede municipal. Em 2016, período de coleta dos dados, o município contava com 72 alunos para quatro salas de recursos. Alguns alunos fazem atendimento nas SRM do município e outros nos CAEE.

A fim de explorar informações acerca do quantitativo de alunos PAEE e número de SRM em cada município, apresenta-se os dados na tabela que segue, referente a taxa de alunos atendidos por SRM.

QUADRO 1: Taxa de alunos PAEE por SRM nos municípios de Rio Claro e Santa Maria de Jetibá

\begin{tabular}{|l|c|c|c|c|}
\hline Proporção de alunos & $\begin{array}{c}\text { Número total } \\
\text { de alunos na } \\
\text { rede }\end{array}$ & $\begin{array}{c}\text { Número total de } \\
\text { alunos atendidos } \\
\text { no AEE }\end{array}$ & $\begin{array}{c}\text { Número } \\
\text { total de } \\
\text { SRM }\end{array}$ & $\begin{array}{c}\text { Taxa de alunos } \\
\text { atendidos por } \\
\text { sala }\end{array}$ \\
\hline Rio Claro & 17.331 & 247 & 18 & 13,72 \\
\hline Santa Maria de Jetibá & 3.715 & 72 & 5 & 14,4 \\
\hline
\end{tabular}

Fonte: Dados fornecidos pelos setores de Educação Especial dos municípios pesquisados

As dimensões brasileiras nos desafiam a múltiplos olhares e atravessamentos na implementação das políticas educacionais.

[...] a sua dimensão continental, as profundas desigualdades regionais e a imensa população em idade escolar, evidenciam a pertinência de os estudos na área da Educação Especial se dedicarem a compreender aspectos das políticas locais, focalizando diferentes aspectos da dinâmica dos sistemas municipais e estaduais de ensino no Brasil (SOBRINHO et al, 2015, p. 09).

${ }^{6}$ Decreto ${ }^{\circ}$ 091/2010 cria o Centro de Referência de Educação Inclusiva (CREI) no município de Santa Maria de Jetibá.

RPGE- Revista on line de Política e Gestão Educacional, v.22, n.1, p. 395-409, jan./abr. 2018 ISSN: 1519-9029 
Mesmo falando de dois municípios que tenham contextos territoriais, aspectos econômicos, sociais e dimensão das redes de ensino diferenciados, vemos que estamos falando de desafios muito próximos. Esse tempo ainda não representa mudança, seja na implementação, sejam nos processos.

Mais que contextualizar os municípios, a intenção neste momento é dialogar com os gestores e professores que participaram das pesquisas, na busca por aproximações e distanciamentos entre as duas realidades considerando os aspectos pedagógicos do AEE. Alguns temas emergem nesse processo de análise, os quais passaremos a discutir.

No tocante as formas de identificação dos alunos PAEE e encaminhamento para avaliação em Santa Maria de Jetibá as gestoras do CREI no grupo focal realizado em dez/2015 destacaram que em síntese:

- O professor ao detectar algum aluno com desenvolvimento considerado "divergente" em relação aos demais, preenche uma ficha de encaminhamento com sua percepção pedagógica e anexa à ela um termo de autorização assinado pela família e encaminha para o CREI;

- A Equipe do CREI faz uma pré-avaliação do caso para discutir sobre os apontamentos realizados pelo professor e fazer os devidos encaminhamentos. Há casos de direcionamento desse aluno para acompanhamento com outros profissionais (Pedagogo, Fonoaudiólogo...) ou para triagem na (Associação de pais e amigos dos excepcionais) APAE;

- A Equipe multidisciplinar da APAE (fisioterapeuta, nutricionista, fonoaudiólogo, psicólogo, pedagogo, dentista e assistente social) realiza a avaliação e, em alguns casos, é solicitada avaliação do neuropediatra e/ou geneticista;

- Finalizado o processo investigatório pela APAE - emissão do laudo confirmando se o aluno tem ou não alguma deficiência - a partir daí o CREI realiza o acompanhamento desse aluno pelo Plano de Desenvolvimento Individual (PDI) e as Escolas o colocam como dado no Censo (a Secretaria também faz um censo interno).

No município de Rio Claro, a suspeita inicial também era levantada pelo professor do ensino comum, e o caminho percorrido era o encaminhamento do aluno para o professor da SRM. Esse profissional fazia uma pré-avaliação e identificando que o aluno de fato poderia ter alguma especificidade, era realizado o encaminhamento para as instituições competentes para tal função presentes no município. Sendo a suspeita de deficiência intelectual, autismo, condições limítrofes ou superdotação/altas habilidades, o encaminhamento era feito para a 
APAE, que tinha uma parceria com o Núcleo de Diagnósticos para emissão de laudos dessa instituição.

Havia também outra instituição no município, o Centro de Habilitação Infantil (CHI), que a assistente social agendava avaliação com a equipe composta por pedagogo, psicólogo, fisioterapeuta e fonoaudióloga. Tais profissionais avaliavam e decidiam quais os próximos passos a serem dados com a criança. Uma terceira possibilidade era de o laudo ser emitido por médicos do sistema público ou privado, ficando nestes casos a cargo da família fazer o encaminhamento e agendamento.

Podemos observar que a presença da instituição privada em Santa Maria de Jetibá e em Rio Claro (APAE) e da Fundação Municipal de Saúde em Rio Claro (CHI) no processo de identificação do aluno PAEE, retratam a percepção da visão médica predominante no processo de diagnóstico em ambos municípios.

Historicamente, não sem razão, a perspectiva médico-clínica alcançou legitimidade no atendimento às demandas das pessoas com deficiência, e, ao observarmos os debates e reivindicações dos participantes da pesquisa, percebemos argumentos que sustentam a crença de que os profissionais da área clínica são os mais capacitados em identificar os serviços e acompanhamentos do que, de fato, as pessoas com deficiência necessitam para garantir seu desenvolvimento e para sua participação social (SOBRINHO; SÁ; PANTALEÃO, 2017, p. 1310).

Embora ambos municípios destaquem a figura do professor de sala comum e de Educação Especial no diagnóstico, o laudo clínico torna-se fundamental ao processo de encaminhamento para o AEE. Um dos questionamentos que nos fazemos é como esse processo de identificação do aluno, que demonstra uma concepção clínico-terapêutica, pode influenciar o planejamento e execução do trabalho nas SRM pelo professor do AEE?

Desse modo, considerando as recomendações oficiais, os professores do AEE e do ensino comum devem trabalhar de forma vinculada, inclusive para realizarem a construção de um Plano de Desenvolvimento Individual (PDI), que deve fazer a articulação do trabalho a ser desenvolvido na sala comum, na SRM e também com setores da saúde, quando for o caso. Deste modo, são necessários momentos/espaços para que haja o planejamento das atividades a serem desenvolvidas.

Uma gestora do CREI de Santa Maria de Jetibá destacou a necessidade de realizar um trabalho mais próximo do professor. A fala que segue ilustra essa questão: "O que faltava era um planejamento com os professores, muitos não sabiam como trabalhar o aluno com necessidades especiais, deixava ele jogado em um canto brincando e tinha até medo de chegar 
perto" (GESTORA, GRUPO FOCAL 14/12/2015). A partir daí, oportunizou-se a realização de planejamento em conjunto objetivando "sensibilizar" os professores. Foi possível a instituição de um planejamento com total de sete horas mensais.

Em Rio Claro, em relação aos momentos de encontros, as professoras do ensino comum relataram haver conversas no sentido de sanar dúvidas, mas as profissionais das SRM afirmaram ser mais fácil manter contato direto com as professoras quando ambas estavam na escola no mesmo período, isso ocorria apenas quando o atendimento não era feito no contraturno, e sim, quando o aluno era retirado da sala comum para frequentar a SRM. O que nos remete refletir como pensar num trabalho colaborativo entre professor do AEE e professor do ensino comum quando os atendimentos são realizados em Centros de Atendimentos Especializados (CAEE)?

Uma vez construído o PDI, como as redes e os profissionais fazem uso desse plano? Em Santa Maria de Jetibá já se fazia o uso desta ferramenta e nela foram inseridas informações acerca do conteúdo programático a ser trabalhado trimestralmente, as modificações necessárias no conteúdo de acordo com as demandas de cada aluno, as metas a serem atingidas e resultados alcançados (GRUPO FOCAL, ago/2016). Tal documento ficava arquivado num dossiê na SRM bem como nos arquivos da escola.

Em Rio Claro, no ano do estudo, o PDI estava sendo instituído, tendo sido construído pelos professores das SRM juntamente com os professores do ensino comum, com os coordenadores da escola e o diretor, ou pelo menos deveria ser assinado por todos esses ao ser concluído. Os professores das SRM consideraram ser este um importante dispositivo para auxiliar no direcionamento do planejamento.

Considerando as colocações feitas em relação as possibilidades de trabalho compartilhado, restam interrogações se os PDI foram construídos de acordo com as orientações oficiais, se de fato trazem informações do trabalho também a ser realizado nas salas de ensino comum, ou se se restringiam ao AEE, e, por fim, se diante de tal realidade, o trabalho desenvolvido na SRM dava conta de realizar a complementação e a suplementação ao ensino comum.

O estudo realizado por Mendes; Tannús-Valadão (2015) destaca que as práticas de escolarização parecem carecer de um planejamento educacional que leve em consideração tanto o ensino comum, quanto o AEE, e que não tratem esses dois professores de escolarização como independentes. 
No que se refere a avaliação da aprendizagem no ensino comum, em Santa Maria de Jetibá os alunos PAEE participavam normalmente, juntamente com os demais alunos, e contava-se com a colaboração do estagiário e do professor de AEE.

Em muitas escolas, principalmente nas EMEFs, onde que o professor tá ali dentro, junto, no dia a dia. [...] no dia da avaliação já tá lá modificadinha e o aluno faz também a avaliação com os demais alunos. Aí o estagiário ele vai as vezes funcionar como um auxílio ledor, transcritor, enfim (GESTORA 1, GRUPO FOCAL 14/12/2015).

Em Rio Claro, uma professora afirmou que todos os alunos matriculados possuíam portfólio para fazer o acompanhamento. Eram atribuídos conceitos referentes ao rendimento dos alunos, e a fala da coordenadora explica tal fato: " $3^{\circ}$ e $5^{\circ}$ anos têm conceitos trimestrais e no $1^{\circ}, 2^{\circ}$ e $4^{\circ}$ conceito anual" (p. 31). Desta forma, existiam avaliações periódicas, como em todas as escolas, e para os alunos PAEE não era diferente. As professoras relataram que as avaliações eram voltadas para o que o aluno aprendeu no decorrer do ano, caso o currículo tivesse sido adaptado, a avaliação era baseada nesse currículo.

O processo de avaliação representa um grande desafio para professores e gestores, principalmente quando assumimos uma concepção de avaliação que ultrapassa a quantificação e mensuração. Jesus et al (2015) apontam que a avaliação influencia na sistematização do planejamento dos trabalhos pedagógicos executados nas salas de aula comum e nas SRM, na articulação do currículo escolar com os percursos de aprendizagem dos alunos e na maneira como os professores subjetivam os estudantes e os acompanham.

\section{Considerações finais}

Buscamos ao longo deste texto refletir temáticas sobre o AEE a partir dos contextos e vozes dos profissionais de dois municípios da região sudeste do Brasil. Esse exercício do diálogo apresentou-se desafiador, uma vez que numa perspectiva dos estudos comparados, buscamos considerar o outro não mais como objeto de investigação a ser compreendido, e a prática não como preocupação secundária, como aponta Devechi e Tauchen (2015).

Muitas reflexões ainda são necessárias para compreender as políticas a partir dos atores que as colocam em uso, seus discursos e às práticas institucionais que emergem do processo de implementação das políticas pelos profissionais que atuam no nível da prática (MAINARDES, 2006). Em se tratando do AEE, ofertado nas SRM, as políticas voltadas para esta forma de atendimento são recentes e, por isso, há muito que se constituir para se saber de fato como ensinar nestas salas. Além disso, o atendimento ao PAEE necessita de mudanças 
sobre o fazer pedagógico e, também, na organização e no planejamento das atividades escolares, visto as suas diversas individualidades.

Apostamos na necessidade de outros diálogos como este, que tragam os diferentes atores dos contextos locais das redes de ensino de diferentes municípios do Brasil, em seus significados sociais, culturais e históricos. Essa é uma aposta sobre as compreensões sobre o mundo, os preconceitos em relação aos grupos poderiam ser minimizados, reduzindo a distância entre os indivíduos, sem retrair as diferenças (DEVECHI; TAUCHEN, 2015).

\section{REFERÊNCIAS}

ALMEIDA, M. L.; JESUS, D. M.; CUEVAS, M. R. C. Formação continuada de gestores públicos de educação especial pela via da pesquisa-ação: o caso da Região Sudeste e do Caparaó/ES. In: VICTOR, S. L.; DRAGO, R.; PANTALEÃO, E. (Org.). Educação especial no cenário educacional brasileiro. São Carlos: Pedro \& João, p. 101-126, 2013.

BALL, S. J.; BOWE, R. Subject departments and the "implementation" of National Curriculum policy: an overview of the issues. Journal of Curriculum Studies, London, v. 24, n. 2, p. 97-115, 1992.

BARDIN, L. Análise de conteúdo. Lisboa: Edições 70, 1994.

BRASIL. Resolução CNE/CEB no 2, de 11 de setembro de 2001. Institui Diretrizes Nacionais para Educação Especial na Educação Básica/Secretaria de Educação Especial. Brasília. 2001. Disponível em: 〈http://portal.mec.gov.br/cne/arquivos/pdf/CEB 0201.pdf〉. Acesso em: 10 mar. 2017.

BRASIL. Política Nacional de Educação Especial na Perspectiva da Educação Inclusiva, Brasília, 2008. Secretaria de Educação Especial. Disponível em: <portal.mec.gov.br/seesp/arquivos/pdf/politica.pdf>. Acesso em: 20 mar. 2017.

BRASIL. Resolução no 4, de 02 de outubro de 2009. Institui Diretrizes Operacionais para o Atendimento Educacional Especializado na Educação Básica, modalidade Educação Especial. Secretaria de Educação Especial. Brasília, 2009. Disponível em:

<portal.mec.gov.br/dmdocuments/rceb004_09.pdf>. Acesso em: 30 nov. 2016.

BRASIL. Instituto Nacional de Estudos e Pesquisa Educacional Anísio Teixeira - INEP. Microdados do Censo Escolar da Educação Básica - 2016. Disponível em: <http://portal.inep.gov.br/microdados>. Acesso em: 20 mar. 2017.

CAIADO, K. R. M.; LAPLANE, A. L. F. Programa Educação inclusiva: direito à diversidade: uma análise a partir da visão de um município-pólo. Educação e Pesquisa, v. 35, p. 303-315, 2009.

CARARO, M. F. O programa mais educação e suas interfaces com outros programas sociais federais no combate à pobreza e à vulnerabilidade social: intenções e tensões. 2015. 328 f. Tese (Doutorado em Educação) - Programa de Pós-Graduação em Educação, Universidade Federal do Espírito Santo, Vitória, 2015. 
DEVECHI, C. P. V.; Tauchen, G. O Futuro da educação comparada: das interpretações de mundo à comunicação com o outro? Reunião Nacional da ANPED, 37, 2015, Florianópolis. Plano Nacional de Educação: tensões e perspectivas para a educação pública brasileira, 2015.

GARCIA, R. M. C. Política de Educação Especial na perspectiva inclusiva e a formação docente no Brasil. Revista Brasileira de Educação, Rio de Janeiro, v. 18, n. 52, p. 101-239, 2013.

GATTI, B. A. Grupo focal na pesquisa em ciências sociais e humanas. Brasília: Líber Livro, 2005.

HABERMAS, J. Teoria de la accion comunicativa: racionalidad de la acion y racionalizacion social. Version de Manuel Jimenez Redondo. Madrid: Taurus, 1987. 1 v.

HABERMAS, J. Consciência moral e agir comunicativo. 2. ed. Rio de Janeiro: Tempo Brasileiro, 2003.

INSTITUTO BRASILEIRO DE GEOGRAFIA E ESTATÍSTICA - IBGE. IBGE Cidades. 2010. Disponível em: <http://www.ibge.gov.br/>. Acesso em: 10 de maio de 2014.

JESUS, D. M. et al. Atendimento Educacional Especializado e processos de avaliação: o que dizem as narrativas dos professores. Revista Cocar (UEPA), v. 1, p. 8-24, 2015.

MAINARDES, J. Abordagem do ciclo de políticas: uma contribuição para a análise de políticas educacionais. Educação e Sociedade, Campinas, v. 27, n. 94, p. 47-69, abr. 2006.

MENDES, E. G.; TANNÚS-VALADÃO, G. Organização e funcionamento do atendimento educacional especializado em salas de recursos multifuncionais: o que as evidências indicam? In: MENDES, E. G.; CIA, F.; TANNÚS-VALADÃO, G. (Org.). Inclusão escolar em foco: organização e funcionamento do atendimento educacional especializado. São Carlos: Marquezine \& Manzini, p. 501-518, 2015.

MOREIRA, F. A.; REZENDE, V. M.; ISOBE, R. M. R. Investigação comparada em educação: aspectos teóricos e metodológicos. Educação e Políticas em Debate, v. 2, p. 229 248, 2013.

PRIETO, R. G.; PAGNEZ, K. S. M. M.; GONZALEZ, R. K. Educação especial e inclusão escolar: tramas de uma política em implantação. Educ. Real., Porto Alegre, v. 39, n. 3, p. 725-743, set. 2014.

SOBRINHO, R. C. et al. Estudo comparado internacional: contribuições para o campo da educação especial. Rev. bras. educ. espec., Marília, v. 21, n. 4, p. 335-348, dez. 2015.

SOBRINHO, R. C.; SÁ, M. G. S. C.; PANTALEÃO, E. O jogo das garantias dos direitos sociais das pessoas com deficiência. Educ. Real., Porto Alegre, v. 42, n. 4, p. 1303-1317, dez. 2017. 


\section{Como referenciar este artigo}

ALMEIDA, Mariangela Lima de.; MILANESI, Josiane Beltrame.; MENDES, Enicéia Gonçalves. A produção de conhecimentos sobre atendimento educacional especializado: um estudo comparado nacional. Revista on line de Política e Gestão Educacional, Araraquara, v.22, n.1, p. 395-409, jan./abr., 2018 ISSN: 1519-9029. DOI: 10.22633/rpge.v22.n.1.2018.10722

Submetido em: 29/11/2017

Aprovado em: 30/01/2018 